\title{
Plasticity of Acquired Secondary Metabolites in Clathria prolifera (Demospongia: Poecilosclerida): Putative Photoprotective Role of Carotenoids in a Temperate Intertidal Sponge
}

\author{
Jonathan D. Dattelbaum ${ }^{1}$, Drew Sieg ${ }^{2}$, Chris M. Manieri ${ }^{1}$, Giles Thomson ${ }^{3}$ and Malcolm Hill ${ }^{*}, 3$ \\ ${ }^{1}$ Department of Chemistry, University of Richmond, Richmond, Virginia 23173, USA \\ ${ }^{2}$ Department of Biology, Georgia Institute of Technology, Atlanta, Georgia 30332, USA \\ ${ }^{3}$ Department of Biology, University of Richmond, Richmond, Virginia 23173, USA
}

\begin{abstract}
Several marine sponges sequester high concentrations of carotenoids in their tissues. The diversity of carotenoid compounds has been described in detail for a handful of species, but to date, little attention has been paid to natural variability in the concentration and constituency of carotenoid pools. Also lacking are experimental tests of some of the proposed adaptive benefits of carotenoids to the sponge. To address some of these deficits in our understanding of sponge ecology, we used a combination of analytic chemistry, field surveys, and manipulative experiments to determine what function these compounds might play. Attention was focused on the common, carotenoid-rich intertidal sponge Clathria (Microciona) prolifera from Chesapeake Bay, Virginia, USA. Surveys of pier pilings indicated that C. prolifera was most common towards the surface of the water, with an average depth of $1 \mathrm{~m}$, and also occurred most frequently on pilings exposed to sunlight. Total carotenoid concentrations (as estimated from spectroscopy) were maximal when solar radiation was nearing its northern maximum. However, HPLC analysis of crude acetone extracts highlighted several instances where concentrations of individual putative carotenoids were maximal during thermal (not solar) maxima in Chesapeake Bay. Naturally occurring sponges growing in environments protected from direct sunlight were found to have significantly lower total carotenoid concentration. In a manipulative field experiment, sponges transplanted from exposed habitats to shaded habitats showed significant decreases in carotenoid concentrations. HPLC analysis demonstrated that concentrations for several of the pigmented compounds decreased under reduced light levels. Given that sponges do not produce carotenoids de novo, the ecological role that these compounds play in sponge physiology deserves greater attention. Our findings indicate that solar radiation is an important factor in shaping carotenoid profiles of C. prolifera. While the physiological role and ultimate source of these compounds remains unclear, our data point to an adaptive function and indicate that $C$. prolifera is a useful species to address these questions.
\end{abstract}

Keywords: Sponge, secondary metabolites, carotenoids, Clathria prolifera, Chesapeake Bay.

\section{INTRODUCTION}

Carotenoids are a complex family of pigmented compounds commonly derived from a 40 -carbon polyene chain [1]. Approximately 600 types/structures of carotenoids occur naturally, and these are most often produced by bacteria, archaea, algal protists, and fungi [2]. These compounds play vital roles in a variety of important physiological functions (e.g., photosynthesis, photoprotection, and as antioxidants) [1]. While metazoans do not synthesize carotenoids de novo, a variety of animals can sequester these compounds, often at high concentrations (e.g., [3, 4]). The ultimate source of these compounds varies, but for many animals, diet is the primary route of entry into the body (e.g., [5]). Carotenoidbased pigmentation is common among marine invertebrates and vertebrates, and is presumed to perform a variety of functional roles $[6,7]$. For example, sequestered carotenoids in echinoids reduced disease-induced spine loss through increased phagocytic activity and enhanced reproductive

*Address correspondence to this author at the Department of Biology, University of Richmond, Richmond, Virginia 23173, USA; Tel: 8042876628; Fax: 8042898233; E-mail: mhil12@richmond.edu success [8], and provided photoprotection and reproductive benefits [9]. Indirect (i.e., non-physiological) reproductive benefits may also accrue through sexual selection given the large number of organisms that employ carotenoids as signals to potential mates [10].

Carotenoids have been isolated from many marine sponges, and are particularly abundant and diverse among the poecilosclerids and axinellids $[11,12]$. Sponge carotenoids can either remain structurally unmodified from their original symbiont or diet source, or are subsequently modified by the sponge after sequestration (e.g., [12-17]). However, the functional significance of sponge carotenoids remains obscure. Given the lack of a sensory system, sexual selection is an unlikely force acting to shape sponge carotenoid profiles. Thus, it is more likely that carotenoids play an ameliorative physiological role in sponge biology, though this idea remains untested.

For sessile marine invertebrates that live in intertidal or shallow sub-tidal zones, solar radiation, especially ultraviolet radiation (UVR; 290-400 nm), can be a significant stressor (e.g., [18-24]). This portion of the electromagnetic spectrum has the potential to penetrate water to $20 \mathrm{~m}$ [18], and has 


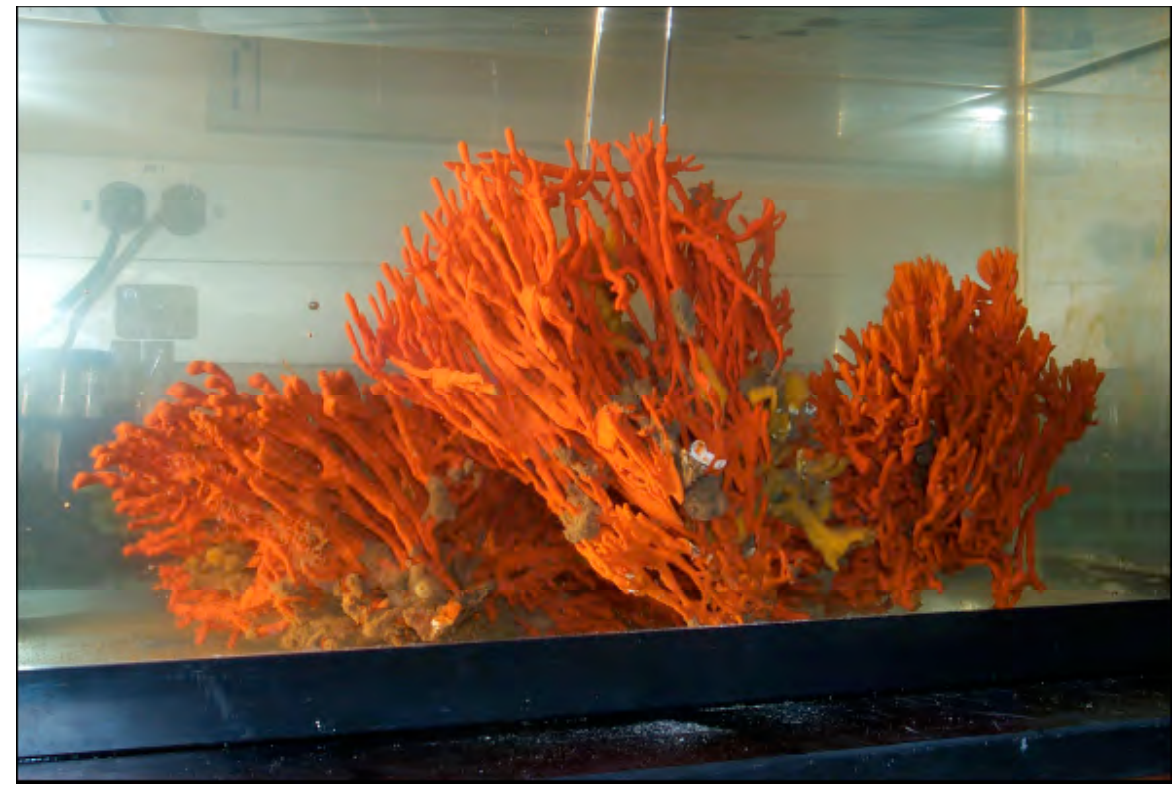

A

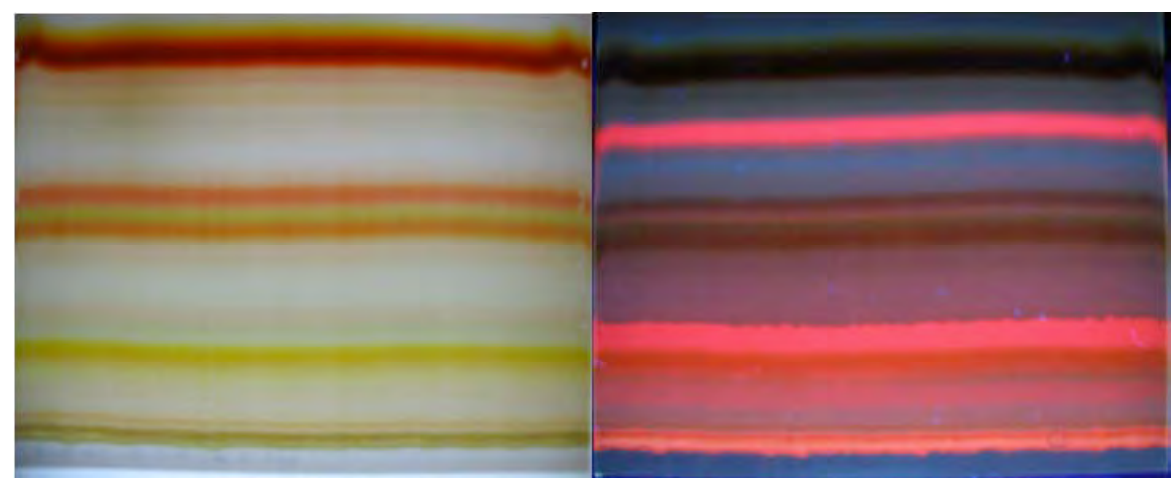

B

Fig. (1). Clathria prolifera A) A freshly collected sponge photographed in an aquarium in the lab. The bright red color is due to abundant, intracellular pools of carotenoids. B) Thin layer chromatography (TLC) of acetone extracts from C. prolifera show the diversity of carotenoids (and other pigments) found in this sponge. The image on the left is taken under visible light, the image on the right is of the same TLC plate under UV light.

likely been a strong selective force in the history of shallow water organisms because a number of protective mechanisms exist to deal with UVR-induced damage (e.g., [21, 24-26]). Although organisms from lower latitudes (especially coral reefs) have been a major focus of studies examining photoprotection (e.g., [25, 27]), higher latitudes also experience physiologically challenging periods where solar radiation intensities can exceed those found in the tropics (i.e., the summer months) [28, 29].

One of the consequences of prolonged exposure to high light intensity is that reactive oxygen species (ROS) such as singlet oxygen $\left({ }^{1} \mathrm{O}_{2}\right)$, superoxides $\left(\mathrm{O}_{2}^{-}\right)$, hydroxyl radicals $(\mathrm{OH})$, and hydrogen peroxide $\left(\mathrm{H}_{2} \mathrm{O}_{2}\right)$ can be generated by UVR [20]. These ROS can damage cells through the oxidation of proteins, lipids and DNA [30]. A number of enzymatic (e.g., super oxide dismutase, catalase) and/or nonenzymatic photoprotective mechanisms exist [31, 32]. Carotenoids make up one class of non-enzymatic compounds that is particularly effective against oxygen radicals (e.g., [33]). These pigments present a diversity of colors depending on the wavelength of maximum absorption, which is directly related to the number of conjugated double bonds in the molecule [1]. It has been suggested that the diversification of carotenoids (e.g., xanthophylls) may have served as a "rudimentary antioxidant system" in response to the appearance of oxygen on the planet 3-2.5 billion years ago [28].

We examined the poecilosclerid "red-beard sponge" Clathria (Microciona) prolifera (Fig. 1A) to assess the role that carotenoids may play in this species. This species bright red coloration is due to abundant and complex carotenoids within its tissues (Fig. 1B). Litchfield and Liaaen-Jensen [14] conducted a thorough survey of the types of carotenoids found in this sponge. However, they only used sponges collected during the summer in their analysis. To add a temporal component to the previous work, we followed carotenoid concentrations over the course of several months. We also examined the potential photoprotective role of carotenoids by comparing populations of $C$. prolifera growing in illuminated and shaded habitats. A transplant experiment 
between shaded and exposed sites was also conducted to determine if carotenoid pools shift in predicted directions.

\section{METHODS AND MATERIALS}

\section{Sponge Collections and Surveys}

Surveys of Clathria prolifera populations were conducted along a wooden pier system that existed at the Virginia Institute of Marine Science (VIMS) campus at Gloucester Point, Virginia (37.25 N, 76.50 W). Fifteen rows of pilings with nearly 150 individual pilings (6-9 per row) as well as the substratum between the rows of pilings were randomly selected for analysis. We examined the depth distribution of adult $C$. prolifera by comparing their position relative to the approximate mean low-low water mark (LLW) on each piling as determined by the algal and barnacle line. We determined whether the observed distribution was statistically different from normal using the Shapiro-Wilk W Goodness-of-Fit test. We also compared sponge density (individuals $\mathrm{m}^{-2}$ ) on exterior pilings (exposed to sunlight), internal pilings (shaded throughout the day), and the substratum. Statistical comparisons were made with a one-way ANOVA followed by Tukey's HSD. Light levels and temperature profiles were measured in each of the habitats with Hobo $^{\text {TM }}$ Pendant Underwater Temperature/ Light loggers.

For seasonal collections, $C$. prolifera samples $(\approx 10 \mathrm{ml}$ in size) were collected monthly from the VIMS pier. Samples from $\geq 10$ individuals were collected at the LLW mark from exterior portions of pilings along the pier (i.e., sponges exposed to direct sunlight). Samples were transported to the lab in aerated tanks and were processed within 4 hours of collection. Sponges were quickly frozen to $-80^{\circ} \mathrm{C}$ and then lyophilized. A powder was created from freeze-dried sponge material in a standard coffee mill. The resulting material was stored in airtight containers at $-80^{\circ} \mathrm{C}$ until further processing. Carotenoid concentrations were compared among months using a one-way ANOVA. Multiple comparisons were performed using Tukey's HSD test.

The VIMS pier had a pump house that covered approximately $60 \mathrm{~m}^{2}$, and this structure created a low light environment for the pilings under the pump house (with levels lower than those measured on the internal pilings (see above)). We collected 5 individuals of $C$. prolifera from beneath the pump house, and 5 individuals from exposed pilings near this location in mid-June. Samples were transported to the lab in aerated tanks and were processed as above within 4 hours of collection. Average carotenoid concentrations between the two populations of sponges were compared using a two-tailed Student's t-test.

Given that light levels and amount of water flow could be confounded and confounding factors, we also assessed relative rates of water motion around pilings in exposed locations and under the pump house using the well-known 'clod-card' technique (modified from [34]). Plaster-ofParis $^{\mathrm{TM}}$ clods were molded in plastic egg containers and attached to Plexiglass ${ }^{\mathrm{TM}}$ plates with rubber cement. Clods were attached to pilings using cable ties, and were kept in the field for two days until nearly $50 \%$ of the clod had eroded due to water motion. At that point, clods were transported to the lab, rinsed quickly in distilled water, dried to constant weight at $60^{\circ} \mathrm{C}$, and weighed. Statistical comparisons were made on rates of clod card dissolution between interior and exterior pilings using a two-tailed Student's t-test.

\section{Transplant Experiment}

Five large $C$. prolifera sponges were collected from a series of well-exposed, southward facing pilings at the VIMS pier. Two fist-sized segments were removed from each sponge and placed in mesh bags. One of the segments was affixed to pilings under the pump house (i.e., low light treatment), while the other segment was affixed to pilings exposed to full sunlight (i.e., high light treatment). The mesh bags were then attached to wooden pilings at the LLW mark in mid-July. We ran our experiment through the period of temperature maxima at the VIMS site (see http://web.vims. edu/data_archive/pier/ for archival water temperature data). The maximum and minimum temperatures recorded during our experiment were $29.4^{\circ} \mathrm{C}$ and $23.6^{\circ} \mathrm{C}$ respectively. Sponges were collected after nearly $80 \mathrm{~d}$ (i.e., in early October), which represented the period before water temperatures showed a major decrease. Two of the replicates attached to exposed pilings were not present at the final collection. At the conclusion of the experiment, samples were transported to the lab in aerated tanks and were processed within 4 hours of collection. Sponges were quickly frozen to $-80^{\circ} \mathrm{C}$ and lyophilized. As described above, freeze-dried sponge material was ground and stored at $-80^{\circ} \mathrm{C}$ until processing. Given the nature of our hypothesis, statistical comparison was performed using a one-tailed t-test.

\section{Carotenoid Extration and Analysis}

Samples of the sponge powder $(0.1 \mathrm{~g})$ were extracted twice in a constant volume of HPLC grade acetone for 30 minutes in the dark at $4^{\circ} \mathrm{C}$. Longer extractions did not yield higher concentrations of product so our extraction efficiencies were maximal after 1 hour. The two extracts were combined, filtered through a $0.2 \mu \mathrm{m}$ syringe filter, and stored at $-20^{\circ} \mathrm{C}$ in an airtight and light proof container. Samples prepared and stored in this fashion were shown to be stable (i.e., no changes in HPLC traces) for $>4$ months as determined by total absorption and HPLC analysis. Based on the work of Litchfield and Liaaen-Jensen (1980) [14], the major pigmented compounds found in $C$. prolifera are known to be carotenoids, all of which have very similar extinction coefficients [1]. We determined carotenoid concentrations by constructing a standard curve using beta-carotene as a reference compound. Reverse phase HPLC was performed using an Agilent 1100 series instrument equipped with a G1313A auto-sampler and a G1314A UV/Vis detector set to $470 \mathrm{~nm}$ on a Zorbax C-18 column ( $5 \mu \mathrm{m}$ particle size, $2 \mathrm{~mm}$ x $150 \mathrm{~mm})$. Samples $(50 \mu 1$ per run) were separated for $60 \mathrm{~min}$ using an isocratic elution mixture of 93\% methanol, $6.5 \%$ ethyl acetate, and $0.5 \%$ water. Individual peaks within the HPLC profiles were analyzed by integration using the multipeak fitting function found in the Origin 7.0 (Microcal, Inc.) software package.

\section{RESULTS}

The depth distribution of $C$. prolifera collected at VIMS piers was determined to be statistically indistinguishable 


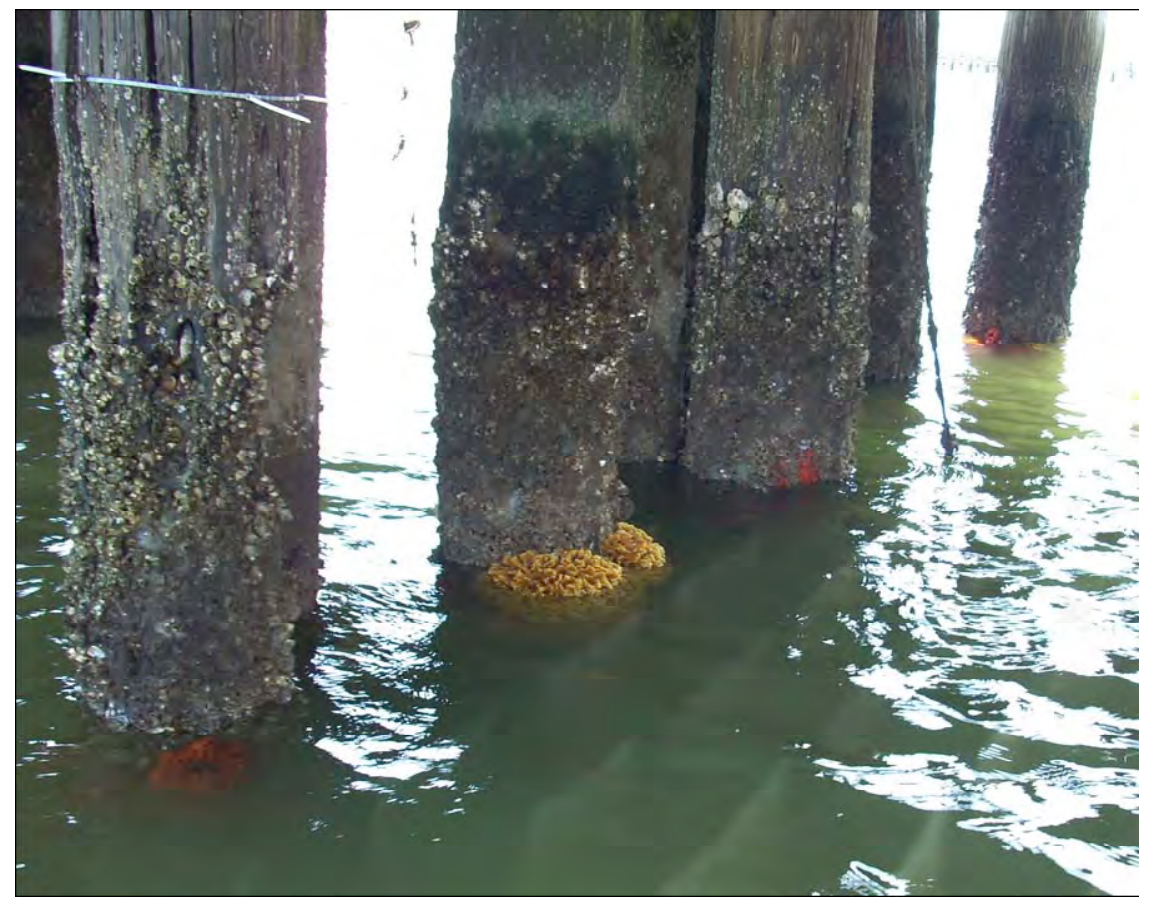

A

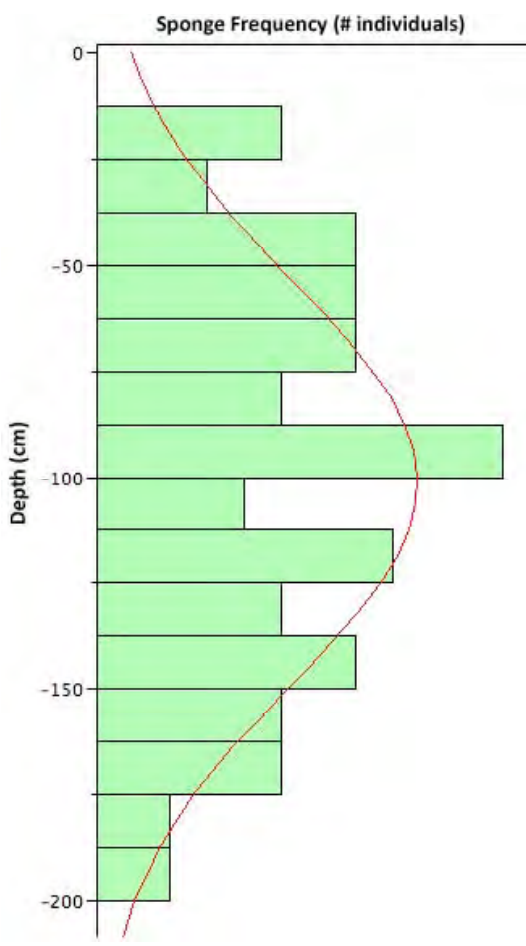

B

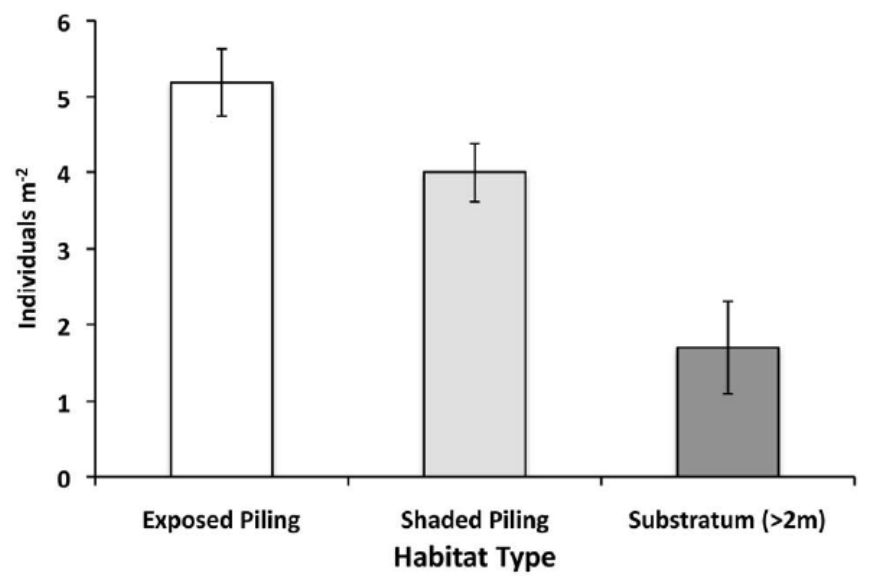

$\mathrm{C}$

Fig. (2). Clathria prolifera distribution at the VIMS pier. A) Pilings associated with the VIMS pier at low tide. Clathria prolifera (red) and Halichondria bowerbanki (yellow) are clearly visible at or above the water surface. B) Frequency distribution of $C$. prolifera along a depth gradient on pier pilings (in relation to mean low water). Average depth for these sponges was $1 \mathrm{~m}$, and the distribution was statistically indistinguishable from normal (red line). C) Significant differences in average density of C. prolifera were observed among pilings exposed to direct light (white bars), pilings protected from light (light grey bars), and the substratum at $2 \mathrm{~m}$ depth (One-way ANOVA, $C p$, $\mathrm{F}_{2,147}=8.4$, $\mathrm{p}<0.001)$. Each habitat was significantly different from the other according to Tukey's HSD test.

from a normal distribution $(\mathrm{W}=0.95 ; \mathrm{p}=0.56$; Fig. 2B), with a population averaging $1 \mathrm{~m}$ depth below the LLW mark on the pilings (Fig. 2B). The average depth at these pilings was found to be $>2 \mathrm{~m}$ indicating that $C$. prolifera favors shallower water at this site. While exposed sponges were often observed during substantial low tides, and $C$. prolifera were often exposed to air for close to an hour during these periods (Fig. 2A), the number of individuals exposed during low tides represented a small percentage of the entire popu- 
lation. Our surveys also uncovered significant differences (ANOVA, $\left.\mathrm{F}_{2,147}=8.4, \mathrm{p}<0.001\right)$ in average sponge density among piling types and the sea floor (Fig. 2C). Pilings exposed to high light levels had the highest density of $C$. prolifera whereas the sea floor had the lowest sponge densities. Data collected with the Hobos ${ }^{\mathrm{TM}}$ indicated that interior pilings experienced a $60 \%$ reduction in ambient light compared to exterior pilings, and light levels at $2 \mathrm{~m}$ depth were $<90 \%$ that of the surface (data not shown). No significant differences in water motion between exterior and internal pilings were observed $\left(\mathrm{t}_{19}=0.25 ; \mathrm{p}>0.4\right)$.
Carotenoid concentrations exhibited clear seasonality (Fig. 3A) with significant differences observed among months (ANOVA, $\mathrm{F}_{6,63}=13.5 ; \mathrm{p}<0.001$ ). May was found to have the highest concentration of carotenoids, while March had the lowest. April, August and September were not different from one another, but all other months were significantly different (according to Tukey's HSD). An interesting pattern was uncovered when crude acetone extracts were examined via HPLC on pooled samples from $\geq$ 10 individuals from each month (Fig. 3B). Three peaks (4-6) with elution times of $28.8,32.5$, and 36.1 min respectively,

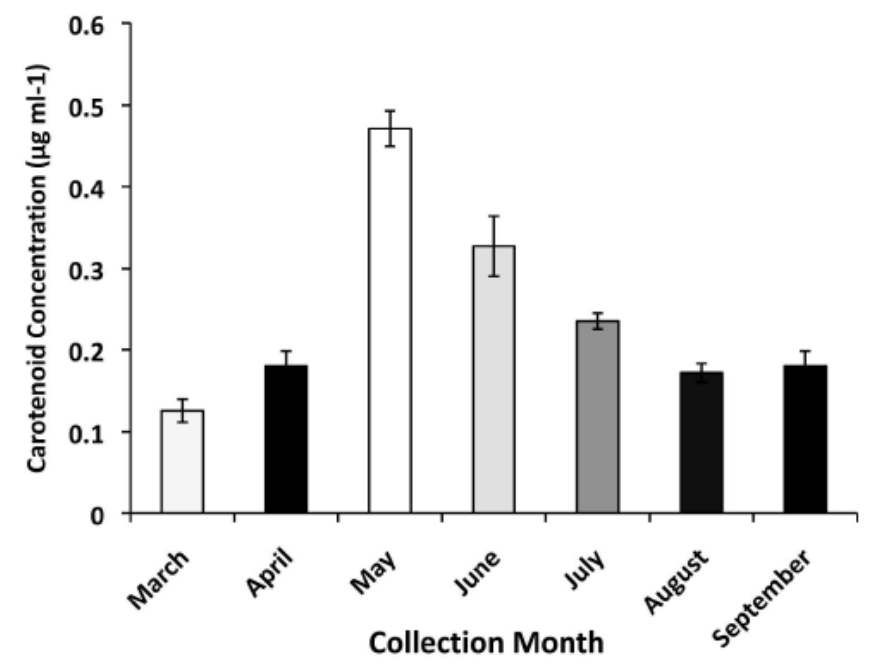

A

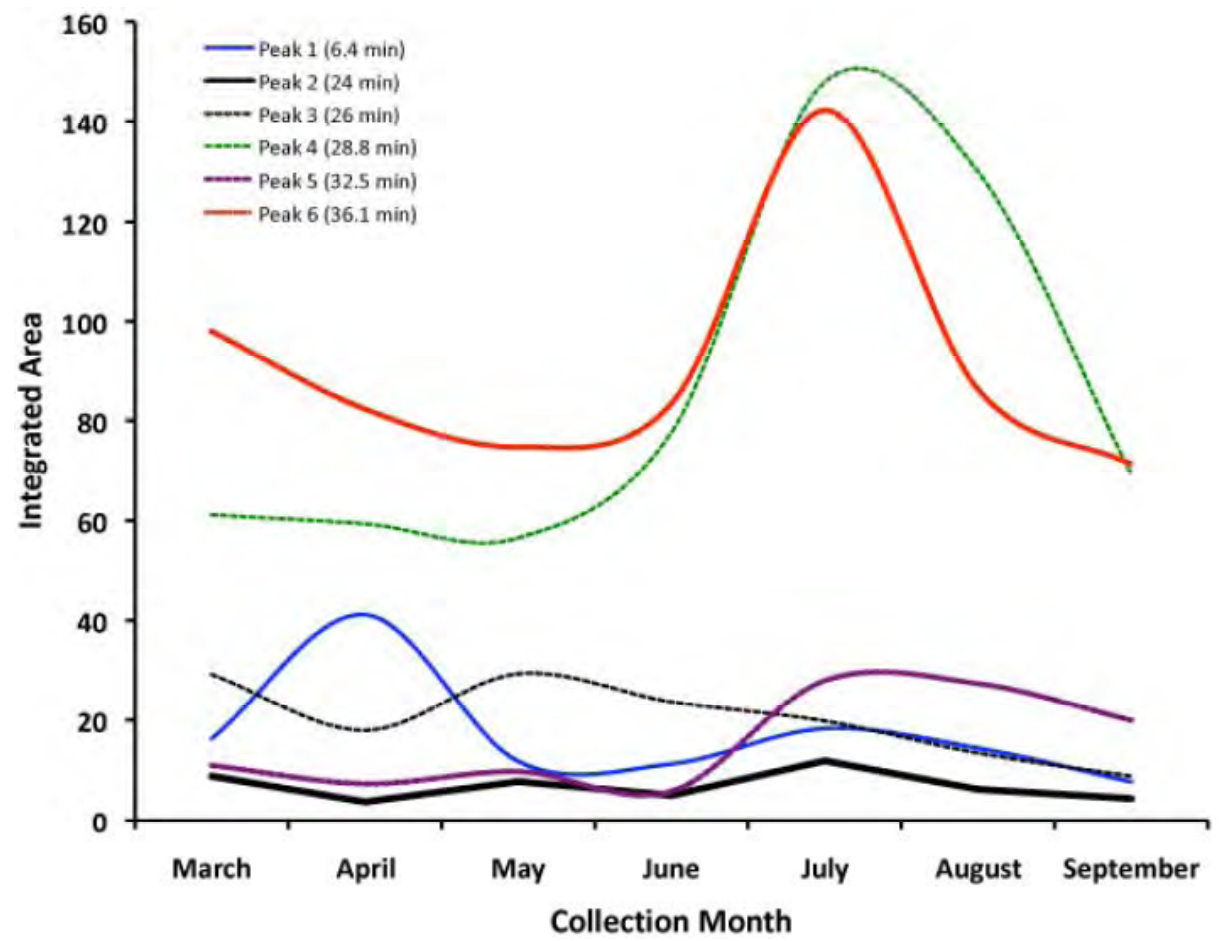

$\mathrm{B}$

Fig. (3). Seasonal carotenoid profiles. A) Carotenoid concentrations for C. prolifera were found to peak in May. One-way ANOVA showed that only April, August and September were not significantly different from each other. Bars differing in color are significantly different at $\mathrm{p}$ $<0.05$ (Tukey's HSD). B) Each line follows a specific peak in the HPLC runs of crude acetone extracts from pooled samples ( $\geq 10$ individual sponges). Peaks 4-6 (elution times $28.8 \mathrm{~min}, 32.5 \mathrm{~min}$, and $36.1 \mathrm{~min}$ respectively) were maximal in July and August. Peak 1 (elution time 6.4 min) was maximal in April. Peaks 2 and 3 showed no seasonal trend (i.e., minor fluctuations) over the time course studied. 


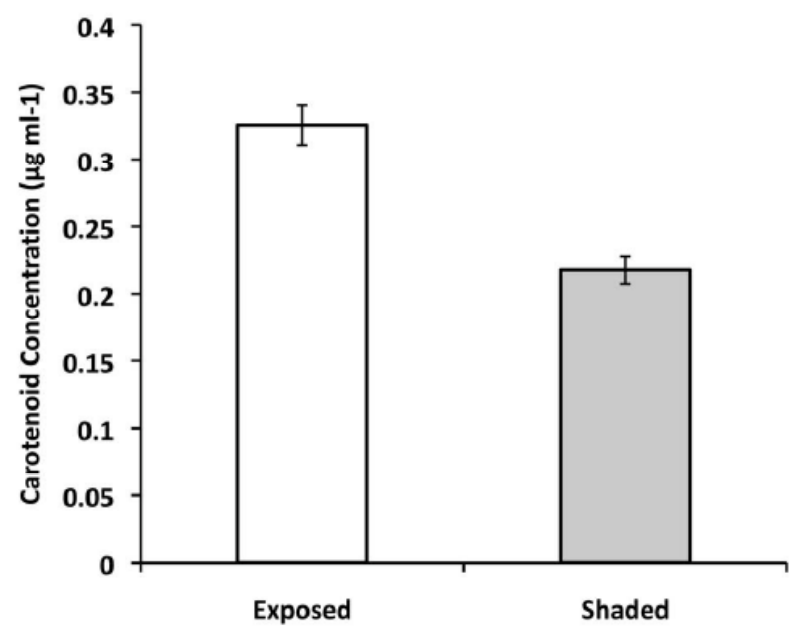

A

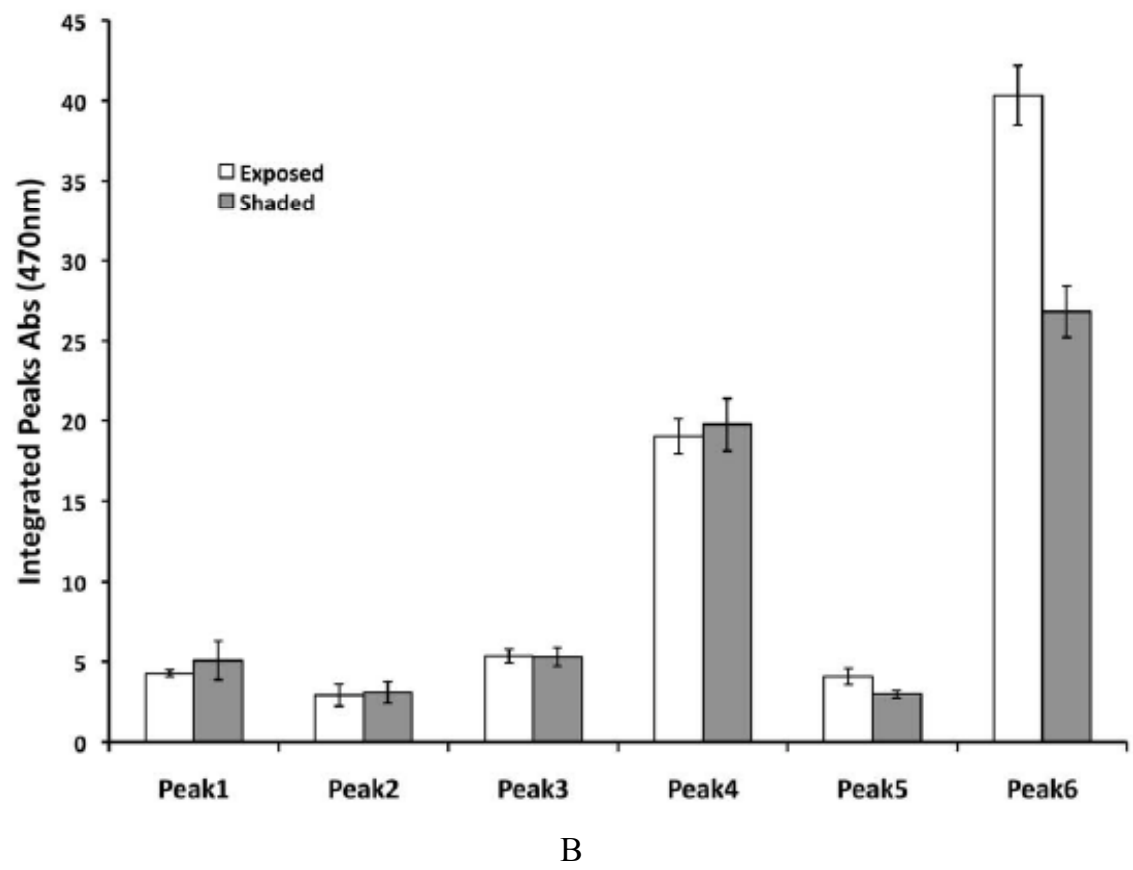

Fig. (4). Natural carotenoid concentrations in illuminated and shaded habitats. A) Sponges naturally growing in shaded locations were found to have significantly lower concentrations of carotenoids than sponges growing in exposed locations. B) Significant differences in unidentified compounds were found in Peaks 4 and 5 (elution time $28.8 \mathrm{~min}$ and $32.5 \mathrm{~min}$ respectively) of our HPLC runs. No other peaks differed between the two treatments.

were at their highest concentration in July and August. This is a different pattern than emerged with the total carotenoid concentration observed above. Indeed, the compound(s) with an elution time of $6.4 \mathrm{~min}$ had its highest value in April (Fig. 3B).

Naturally occurring sponges growing in shaded and exposed habitats had significantly different total carotenoid concentrations (Fig. 4A). These differences might be driven by reductions in two of the compounds distinguished via HPLC (see Peaks 5 and 6; Fig. 4B). Sponges transplanted to shaded habitats showed a significant reduction in total carotenoid concentration $\left(t_{6}=1.95 ; p<0.05 ;\right.$ Fig. 5A $)$. The HPLC runs (Fig. 5B) showed that significant differences for compounds eluted at time 6.4 and 36.1 min (Peaks $1\left(\mathrm{t}_{6}=\right.$ $2.54, \mathrm{p}<0.05)$ and $6\left(\mathrm{t}_{5}=3.44, \mathrm{p}<0.01\right)$ respectively).

\section{DISCUSSION}

The majority of work on carotenoids in sponges has focused on two questions. The first is, what types/diversity of carotenoids are present in sponge tissue? The second question is, what value do carotenoids have for chemosystematics? For several groups of sponges, abundant and diverse carotenoids have been shown to have systematic value $[11,35]$. Less attention has been paid to natural variability in carotenoid levels among and within populations, and even less effort has been spent attempting to determine the functional significance of these carotenoids in sponges that harbor non-trace concentrations. Our goal was to provide a preliminary assessment of natural variability and adaptive significance of carotenoids for a well-studied sponge known to contain extraordinarily 


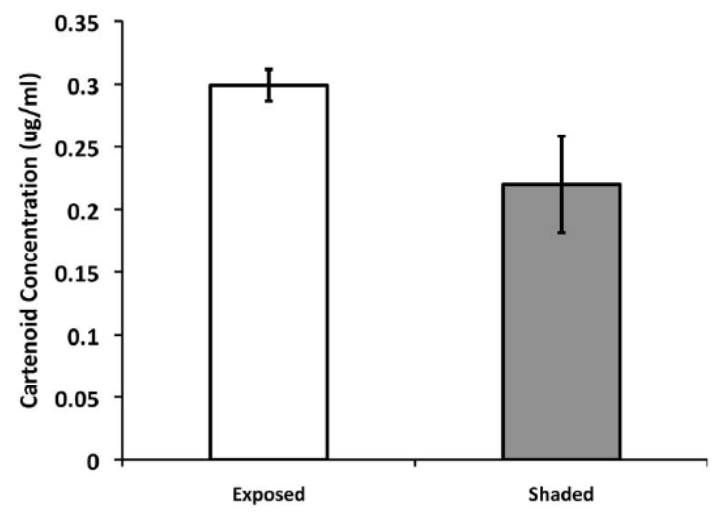

A
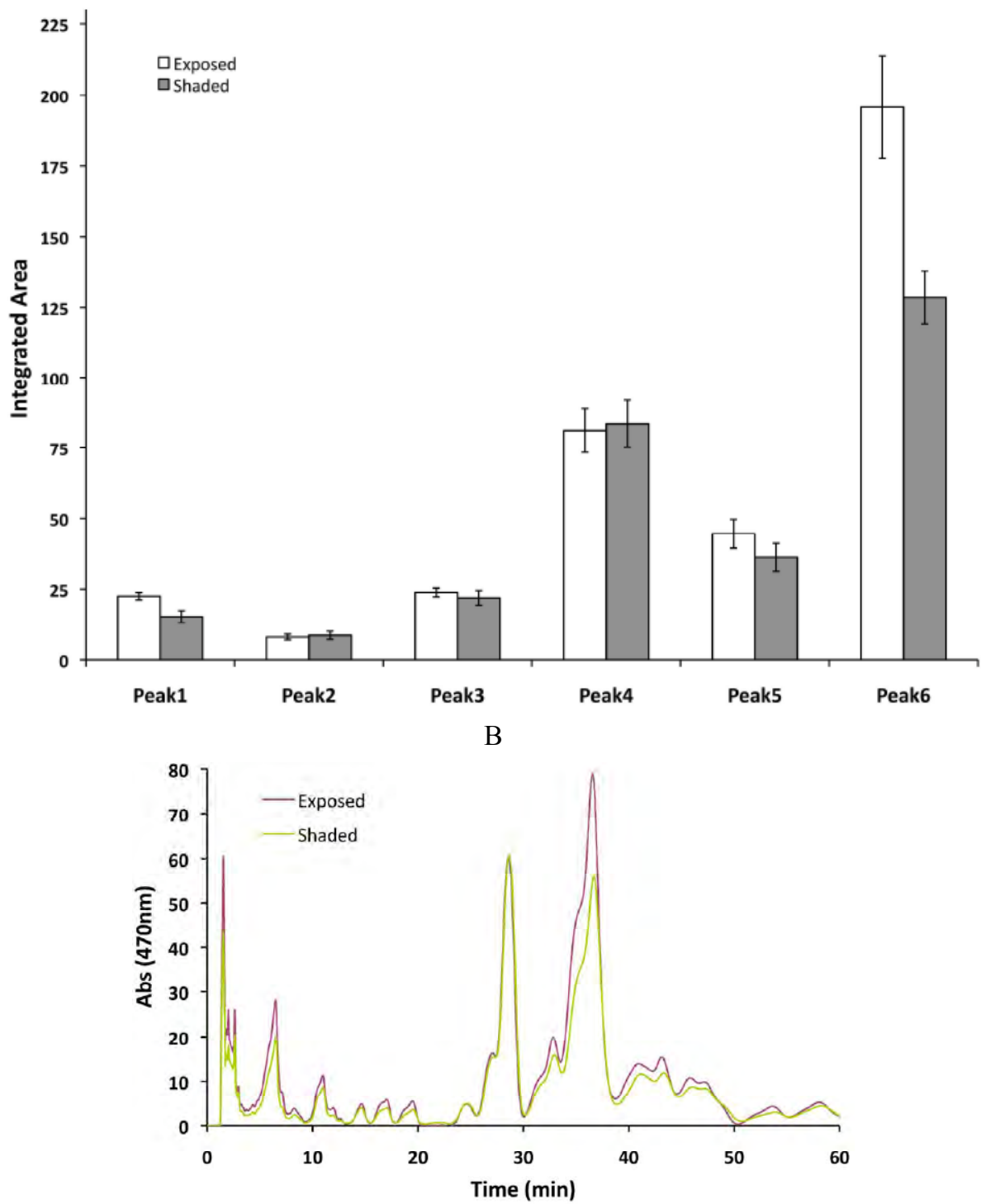

$\mathrm{C}$

Fig. (5). Transplant experiments involving C. prolifera. A) Total carotenoid concentrations showed significant declines in sponges transplanted from exposed locations to shaded locations. B) HPLC patterns highlighted several differences among the treatments. Most notable are the significant differences we observed between treatments in Peaks 1 (elution time 6.4 min; $\mathrm{t}_{6}=2.54, \mathrm{p}<0.05$ ) and 6 (elution time $36.1 \mathrm{~min} ; \mathrm{t}_{5}=3.44, \mathrm{p}<0.05$ ). C) Representative profile of HPLC runs. Average peak values for sponges from the two treatments (i.e., shaded and exposed) are shown.

concentrated and diverse intracellular pools of carotenoids $[14,15]$.
The presence of dominant peaks in every sample we took (e.g., Fig. 5C), regardless of month or habitat type, indicate 
some degree of constancy that might be of chemosystematic value. Thus, our results corroborate findings from earlier studies regarding the systematic utility of carotenoids (e.g., $[12,35,36])$. However, the season variability observed here (Fig. 3) indicates that alternative (constitutively expressed) characters might be preferred, or that, at a minimum, season should be considered as taxonomic comparisons are made. Two studies are of note regarding seasonal variability in carotenoid profiles in sponges. Lee and Klontz (1990) [36] found a large degree of temporal variability in the total carotenoid complement for three sponge species from California. Two of the poecilosclerid sponges used in that study (Plocamia karykima and Ophlitaspongia pennata) showed fairly constant composition of the carotenoid pools, which is consistent with the findings from this study. In contrast to the present study, however, no seasonal pattern emerged [36]. Hooper et al. (1991) [35] also reported interindividual variability among $C$. lendenfeldi and $C$. major sponges. Of the four $C$. ledenfeldi samples, only 3 were collected from the same location but each came from a different season. Each sponge had a distinct pattern, but without larger samples, it is impossible to determine whether the differences are significant or correlate with seasonal changes.

Our surveys indicate that $C$. prolifera found on the VIMS pier are more common on pilings exposed to sunlight (Fig. 2C). While Halichondria bowerbankii, Chalinula (Haliclona) loosanoffi and C. (Haliclona) permollis co-occur on the VIMS pilings, and $H$. bowerbankii is common on the exposed pilings (Fig. 2A), C. prolifera is the most abundant sponge in this habitat (pers. obs.). The role that carotenoids play in shaping the ecological distribution of this sponge deserves greater attention. We hypothesize that carotenoids open habitats that would otherwise be too physiologically stressful (thus expanding the fundamental niche of $C$. prolifera). This hypothesis is not novel (see [30] for a review). For example, Green and Koslova (1992) [37] argued for a photoprotective role of carotenoids in sponges. They found that sponges from the genus Lubomirskia had lower carotenoid concentrations as depth increased (from 2 to $17 \mathrm{~m}$ ) in Lake Baikal. However, light levels and carotenoid availability (i.e., from phytoplankton) are positively correlated with depth making interpretation of their data a challenge. Nonetheless, this is, to our knowledge, one of the first empirical tests aimed at elucidating adaptive functions of carotenoids in sponges.

While carotenoid concentrations in $C$. prolifera were found to change seasonally, it is noteworthy that they can also respond relatively rapidly to changes in the environment (Fig. 5A). This level of plasticity is intriguing for a number of reasons including the fact that the reduction in total carotenoids implies that they are costly to acquire, modify, and/or maintain for the sponge and/or its associated microflora. We hypothesize that $C$. prolifera accumulates carotenoids at a rate proportional to the intensity of ambient illumination (especially UVR). In line with this hypothesis are our observations that $C$. prolifera 1.) exhibits seasonal changes in carotenoid concentrations (Fig. 3), 2.) has significantly higher carotenoid concentrations when growing in well-illuminated habitats (Fig. 4), and 3.) reduces its total carotenoid concentration when transplanted to low-light habitats (Fig. 5). An underlying assumption of this hypo- thesis is that carotenoid maintenance and/or acquisition requires energetic investment, and thus sponges or their symbionts optimally allocate resources to match the stress experienced from illumination (i.e., UVR). C. prolifera provides a model system to test this assumption.

While photoprotection is an attractive hypothesis, it is important to note that alternative hypotheses are possible. For instance, changes in carotenoid concentrations could be driven by light-dependent processes. Carotenoid production rates by microfloral symbionts could be proportional to light availability. It is also possible that carotenoid producing microfloral species increase growth rates in light. Both of the preceding hypotheses would lead to greater carotenoid concentrations under higher light conditions, but neither would necessarily benefit the sponge directly. Distinguishing between the photoprotective hypothesis favored here from these other possibilities will require additional experiments. It is also important to note that photoprotection is just one of several alternative hypotheses regarding the adaptive role carotenoids might play in sponge physiology. Given that $C$. prolifera can be exposed to air for extended periods during spring tides (Fig. 2A), carotenoids might also ameliorate the effects of exposure to the atmosphere (and all the physiological stressors that accompany dessication). Indeed, when sponges face exposure to air and high light levels, ROS may accumulate rapidly. We are currently working to tease apart the specific functions carotenoids play in $C$. prolifera that relate to physiological stress.

Identifying the ultimate source of the carotenoids in $C$. prolifera remains an outstanding question. The diversity of carotenoids and other associated pigments in $C$. prolifera is impressive (Fig. 1B), but the ultimate source of these compounds remains unknown. One of the first carotenoids identified in sponges was suspected to be of symbiotic origin [38], yet many others (especially $\beta$-carotene) are thought to be diet-derived. Other evidence for bacterial-derived carotene production has come from work done on okadaxanthine isolated from Pseudomonas sp. obtained from Halichondria okadai [39]. We know that cuttlefish (Sepia officianalis) harbor a carotenoid-producing bacterium in its nidamental gland [40] but similar associations among the sponges are unknown. The 'costs' that we propose may arise from acquiring and maintaining high concentrations of compounds that are in low concentrations in the natural environment, which would require elevated filtering rates above that are required for basic heterotrophic energetic demands. Alternatively, the sponge may host a microbe that produces a particular compound, but the symbiont exerts a greater physiological cost, and is thus less beneficial to the host sponge. Furthermore, we do not know whether $C$. prolifera's carotenoid pools vary geographically due to symbiont availability or composition of prey in the bacterioplankton.

Our data indicate some intriguing patterns in changes to carotenoid profiles in $C$. prolifera. We propose that the ecological significance of carotenoids is related to how the sponge deals with solar radiation. This hypothesis must be refined, and additional experimental tests are required. Nonetheless, identifying the source of the plastic response (i.e., the cost) should be a major objective of future research. We propose that $C$. prolifera offers a number of useful characteristics to test these ideas. 


\section{ACKNOWLEDGEMENTS}

We would like to thank Brittany West and Ashley McQuillin for help in the field during the transplant experiment. Blake Ramsby and Ericka Poppell provided outstanding assistance during survey work and water flow analyses. Bryan Der, Colin Funaro, Matt Luchansky, Ashley McQuillin, Blake Ramsby, and Brittany West helped with sample collection and data analysis. This research was supported by NSF Biological Oceanography grant (award $\# 0657119)$ to $\mathrm{MH}$ and JDD, a grant from Merck/AAAS, and research support from the School of Arts and Sciences at the University of Richmond.

\section{REFERENCES}

[1] Britton G, Liaaen-Jensen S, Pfander H, Eds. Carotenoids handbook. 1st ed: Birkhäuser Basel 2004.

[2] Johnson EA, Schroeder WA. Microbial carotenoids. Adv Biochem Eng Biotechnol 1995; 532: 119-78.

[3] Lozano GA. Carotenoids, parasites, and sexual selection. Oikos 1994; 70: 309-11.

[4] Møller AP, Biard C, Blount JD, et al. Carotenoid-dependent signals: Indicators of foraging efficiency, immunocompetence, or detoxification ability? Avian Poultry Biol Rev 2000; 11: 137-59.

[5] Carroll M, Hanlon A, Hanlon T, Zangerl AR, Berenbaum MR. Behavioral effects of carotenoid sequestration by the parsnip webworm Depressaria pastinacella. J Chem Ecol 1997; 23: 270719.

[6] Tsushima M, Maoka T, Matsuno T. Comparative biochemical studies of carotenoids in marine invertebrates - the first positive identification of $\varepsilon, \varepsilon$-carotene derivatives and isolation of two new carotenoids from chitons. Comp Biochem Physiol B 1989; 93(3): 665-71.

[7] Matsuno T. Aquatic animal carotenoids. Fish Sci 2001; 67: 771-83.

[8] Kawakami T, Tsushima M, Katabami Y, Mine M, Ishida A, Matsuno T. Effect of beta,beta-carotene, $\beta$-echinenone, astaxanthin, fucoxanthin, vitamin a and vitamin e on the biological defense of the sea urchin Pseudocentrotus depressus. J Exp Mar Biol Ecol 1998; 226: 165-74.

[9] Bandaranayake WM, Des Rocher A. The role of secondary metabolites and pigments in the epidermal tissues, ripe ovaries, viscera, gut contents and diet of the sea cucumber Holothuria atra. Mar Biol 1999; 133: 163-9.

[10] Badyaev AV, Hill GE. Evolution of sexual dichromatism: Contribution of carotenoid- versus melanin-based coloration. Biol J Linn Soc Lond 2000; 69: 153-72.

[11] Hooper JNA, Capon RJ, Keenan CP, Parry DL, Smit N. Chemotaxonomy of marine sponges: families microcionidae, raspailiidae and axinellidae, and their relationship with other families in the orders Poecilosclerida and Axinellida (Porifera: Demospongiae). Invertebr Taxon 1992; 6: 261-301.

[12] Liaaen-Jensen S, Renstrøm B, Ramdahl T, Hallenstvet M, Bergquist P. Carotenoids of marine sponges Biochem Syst Ecol 1982; 10: 167-74.

[13] Eimhjellen KE. Photosynthetic bacteria and carotenoids from a sea sponge Halichondrium panicea. Acta Chem Scand 1967; 21: 22801 .

[14] Litchfield C, Liaaen-Jensen S. Carotenoids of the marine sponge Microciona prolifera. Comp Biochem Physiol 1980; 66: 359-65.

[15] Simpson TL. The cell biology of sponges. Berlin: Springer 1984; p. 662.

[16] Lee WL, Gilchrist BM. Carotenoid patterns in twenty-nine species of sponges in the order Poecilosclerida (Porifera: Demospongiae): A possible tool for chemosystematics. Mar Biol 1985; 86: 21-35.
[17] Sliwka HR, Nokleby OW, Liaaen-Jensen S. Animal carotenoids. 31. Structure elucidation of a sponge metabolite via mesylate elimination. Acta Chem Scand 1987; 41: 245-52.

[18] Gleason DF, Wellington GM. Ultraviolet radiation and coral bleaching. Nature 1993; 365: 836-8.

[19] Lesser MP. Elevated temperatures and ultraviolet radiation cause oxidative stress and inhibit photosynthesis is symbiotic dinoflagellates. Limnol Oceanogr 1996; 41: 271-83.

[20] Lesser MP. Oxidative stress in marine environments: Biochemistry and physiological ecology. Annu Rev Physiol 2006; 68: 253-78.

[21] Dunlap WC, Shick JM, Yamamoto Y. Uv protection in marine organisms. 1. Sunscreens, oxidative stress and antioxidants. In: Yoshikawa T, Toyokuni S, Yamamoto Y, Naito Y, Eds. Free radicals in chemistry, biology and medicine: OICA International 2000; pp. 200-14.

[22] Shick JM, Lesser MP, Jokiel PL. Effects of ultraviolet radiation on corals and other coral reef organisms. Glob Chang Biol 1996; 2: $527-45$.

[23] Hockberger PE. A history of ultraviolet photobiology for humans, animals and microorganisms. Photochem Photobiol 2002; 76: 56179 .

[24] Rozema J, Björn LO, Bornman JF, et al. The role of UV-B radiation in aquatic and terrestrial ecosystems - an experimental and functional analysis of the evolution of UV-absorbing compounds. J Photochem Photobiol B Biol 2002; 66: 2-12.

[25] Lesser MP. Depth-dependent photoacclimatization to solar ultraviolet radiation in the caribbean coral Montastraea faveoloata. Mar Ecol Prog Ser 2000; 192: 137-51.

[26] Adams NL, Shick JM. Mycosporine-like amino acids prevent uvbinduced abnormalities during early development ofthe green sea urchin Strongylocentrotus droebachiensis. Mar Biol 2001; 138: 267-80.

[27] Jokiel PL. Solar ultraviolet radiation and coral reef epifauna. Science 1980; 207: 1069-71.

[28] Johnson FS, Mo T, Green AE. Average latitudinal ultraviolet radiation at the earth's surface. Photochem Photobiol 1976; 23: 179-88.

[29] Campbell JW, Aarup T. Photosynthetically available radiation at high latitudes. Limnol Oceanogr 1989; 34(8): 1490-9.

[30] Halliwell B, Gutteridge JMC. Free radicals in biology and medicine. New York: Oxford University Press Inc 1999.

[31] Fridovich I. Biological effects of the superoxide radical. Arch Biochem Biophys 1986; 247: 1-11.

[32] Regoli F, Cerrano C, Chierici E, Chiantore MC, Bavestrello G. Seasonal variability of prooxidant pressure and antioxidant adaptation to symbiosis in the mediterranean demosponge Petrosia ficiformis. Mar Ecol Prog Ser 2004; 275: 129-37.

[33] Edge R, McGarvey DJ, Truscott TG. The carotenoids as antioxidants-a review. J Photochem Photobiol B Biol 1997; 41: 189200.

[34] Doty MS. Measurement of water movement in reference to benthic algal growth. Botanica Marina 1971; 14: 32-5.

[35] Hooper JNA, Capon RJ, Keenan CP, Parry DL. Morphometric and biochemical differences between sympatric populations of the Clathria "Spicata" Species complex (Demospongiae: Poecilosclerida: Microcionidae) from Northern Australia. Berlin: Springer-Verlag 1991.

[36] Lee WL, Kontz SW. Seasonal and geographic variability in sponge carotenoids. Washington, D.C.: Smithsonian Institution Press 1990

[37] Green J, Koslova T. Carotenoids, photoprotection and food web links in Lake Baikal. Freshw Biol 1992; 28: 49-58.

[38] Liaaen-Jensen S. Recent advances in the chemistry of natural carotenoids. Pure Appl Chem 1967; 14: 227-44.

[39] Miki W, Otaki N, Yokoyama A, Izumida H, Shimidzu N. Okadaxanthin, a novel c50-carotenoid from a bacterium, pseudomonas sp. Kk $10206 \mathrm{c}$ associated with a marine sponge, Halichondria okadai. Experientia 1994; 50: 684-6.

[40] van der Branden C, Gillis M, Richard A. Carotenoid producing bacteria in the accessory nidamental gland of Sepia officinalis. Comp Biochem Physiol 1980; 66: 331-4. 